\title{
Influence of Organization Cultural Internal Integration Perception on New Generation Employees' Job Satisfaction
}

\author{
Yuhua Xie, Jia Chen, and Peipei Chen
}

\begin{abstract}
Using Denison organization cultural traits theory, this paper conducted an empirical study on auto manufacturing industry in China. Specifically, the present study analyzes the influence of cultural internal integration perception both on the new generation employees' and traditional employees' job satisfaction. The empirical results show that two respects of corporate cultural internal integration, involvement and consistency have positively influence on employee's job satisfaction. Intergenerational difference plays a significant moderating role between the involvement perception, consistency perception and job satisfaction. The practical implications are put forward that the managers should fully consider the intergenerational difference in employees, and pay attention to the participation motivation of new generation employees and the formation of team spirit.
\end{abstract}

Index Terms-Organization culture, job satisfaction, intergenerational difference, employee involvement, new generation employee.

\section{INTRODUCTION}

Frequent labor conflicts such as the Nanhai Honda strike and BYD staff rights event have been knocking on the toll of labor relations in China, and the new generation employees in these labor conflicts are causing concern. This new generation group shows higher requirements of working atmosphere and participation in management. Therefore, how to improve their remuneration and how to improve enterprise culture to meet the new generation employees' material and spiritual satisfaction become a hot topic for the management practitioners and scholars.

The automobile industry which is regarded as a complete collection of modern industry has been the focus for scholars in western human resources and labor relations. The establishment and replacement of modern production model, from Ford system to Toyota production mode, are all related to the automobile industry. However, there are little studies in human resources and labor relations based on auto industry in China. In the limited literatures, Zhang Lu paid close attention to workers differentiation in the auto enterprises: the impact of contract workers and outsourcing workers on the factory system; Zhao Wui found out that the workers dissatisfied but still had great expectations to their unions through Hubei auto enterprise survey.

Denison's organization cultural traits theory indicated that

Manuscript received March 27, 2013; revised June 27, 2013.

The authors are with the Management School, Hunan University, Yuelu Mountain, Changsha, Hunan, China (e-mail: yhxie66@aliyun.com, emma715715 @ sina.com, charity137@163.com). the four traits of organization culture (adaptability, mission, consistency, involvement) positively motivate employees' job satisfaction. Auto manufacturing enterprises have more mature organization culture than small and medium-sized enterprises, but how and to what extent the organization culture affects employees' job satisfaction, especially new generation employees', this problem is yet to be researched. Based on four representative auto manufacturing enterprises, this paper investigates the two traits of organization culture internal integration - involvement and consistency which can be directly perceived by workers, explores how the new generation employees' the internal integration perception of organization culture influences their job satisfaction, to find out an effective incentive to new generation employees in the perspective of organization culture.

\section{LITERATURE REVIEW AND HYPOTHESIS}

\section{A. Denison's Organization Cultural Traits Theory}

Organization culture is a kind of standardization of the internalized faith. It can direct employees' organizational behavior, helps to keep the enterprise's targets and improves the employees' work enthusiasm [1].Denison put forward the model assumption of organization cultural traits in 1995: there are four organization cultural traits: Involvement is the construction of employee involvement system; consistency measures the enterprise cohesion of the internal culture; adaptability refers to the company rapid reaction ability of various external conditions; mission determines whether the company is blindly pay attention to immediate interests or focus on the strategic plan. The first two represent the internal integration of organization culture, while the latter two represent the external orientation of organization culture, and all the four are respectively relevant with the organization effectiveness. Further, Denison developed a organization culture scale with two items in each dimension investigating 764 senior managers in American, confirmed the existence of four traits and their significant correlation with organization effectiveness indexes (sales growth, products and service quality, employee satisfaction and overall performance) [2].

Since then, many scholars have use this theory to test the organization culture traits in other countries, and proved the Denison's organization cultural traits model and measurement questionnaire have applicability in Russia [3], India [4] and other countries. Compared with that in United States, the relationship between the organization cultural traits and organization effectiveness is different in other 
countries. Wu Zhongyuan, Zhang Renjiang indicated by empirical study that Denison's organization cultural traits model and measurement questionnaire have applicability in Chinese enterprises, and at the same time Zhang Renjiang also pointed out that in Chinese cultural context, only involvement trait significant positive correlates with employee satisfaction [5]. This is different with Denison's conclusion. Chinese scholars cited the scale directly from Denison, while the sale was not improved in Chinese situation, ignoring the democratic management system in Chinese enterprises [6].In the perspective of organization culture internal integration, the team work and stability [7], employee respect, authorized and reward fairness [8] have significantly positively effect on employee satisfaction. As to auto manufacturing grassroots workers, the two external traits are hard to perceive. Therefore, the following assumptions are put forward:

- Hypothesis 1: The consistency perception of organization culture shows significant positive impact on employees' job satisfaction.

- Hypothesis 2: The involvement perception of organization culture shows significant positive impact on employees' job satisfaction.

\section{B. The New Generation Employees}

Each generation is raised up in different background, resulting in different values and behaviors, which named the intergenerational difference. Foreign research shows that different generation employees have significant intergenerational difference in the personality traits, the attitude to organization, work values, work environment preference and leadership preference. Foreign scholars have done a more thorough research in this aspect, while the domestic workplace research is relatively short. Compared with the traditional employees, Chinese new generation group has characteristics of self realization orientation and interpersonal harmony orientation so that they pay great attention to the collective interests and also pursue for self-value [9].This makes the new generation employees has desires for success and expectations of self value realization. They actively tend to seek development, to work in teams and share fruits of labor in groups, to seek for the fair distribution of wealth and power sharing [10]. New generation employees' work and life values also generate and strengthen their inner motivation remuneration [11]. In addition, new generation employees pursue open and fairness, disgust the traditional hierarchy and more used to the democracy and consultative mode of communication. Compared with traditional employees, new generation group has a higher need of participation in management, while they have a low satisfaction of participation practice. In conclusion, hypothesis as follows:

- Hypothesis 3: Compared to traditional employees, the consistency perception of organization culture shows higher significant positive impact on the new generation employees' job satisfaction.

- Hypothesis 4: Compared to traditional employees, the involvement perception of organization culture shows higher significant positive impact on the new generation employees' job satisfaction.

\section{Methodology}

\section{A. The Division of Generation}

Kupperschmidt defines a generation as an identifiable group, or cohort, which shares birth years, age, location, and significant life events at critical developmental stages. Chinese scholars also agree with this understanding and basically regard "the Cultural Revolutio" and "reform and open" as the intergenerational partition standard. Nowadays the employees in our country's workplace were mostly born after the culture revolution, therefore this paper choose "reform and open" for the division standard. So in data processing, according to the year of birth, the 31 years old and under employees (born after and contain 1980) define as a group; 32 years old and above employees (born before 1980) are divided into another group. Refer to $\mathrm{Wu}$ Hongyu, the former group is defined as the new generation employees, and the latter group is defined as traditional employees.

\section{B. Measures}

The organization culture scale used in this paper refers to the internal integration scale in Denison [2], [12] organization culture scale. Some items are modified combined with the actual situation of Chinese automobile enterprise. Cronbach's $\alpha$ of the scale is 0.814. The involvement scale keeps the items of participation in management and staff development, and adds democratic participation items refer to Xie Yuhua [13]including democratic appraisal, workers conference and so on, with a total 10 items, which the Cronbach 's $\alpha$ is 0.765 ; the consistency scale keeps the items such as identity, integration, cooperation and communication between departments, and adds the interpersonal harmony item in Ji Xiaoli enterprise culture scale, with a total 9 items, which Cronbach's $\alpha$ is 0.724. The job satisfaction scale refers to Spector [14] job satisfaction scale, including 6 items - the working time, income, prospects, labor conditions, atmosphere, and overall satisfaction, which the Cronbach's a is 0.829. Above all scales use Likert five points scale, in which the respondents are given 1 to 5 points, 1 for the minimum degree, 5 for the highest level.

Reliability analysis shows that the scales all reach above 0.7 , so that the overall scale has good reliability. The correlation between the various variables are larger than 0.40 ; the correlation coefficients among the two dimensions of organization culture and the total score are greater than 0.80 , and are all larger than the correlation between the two dimensions. It shows that the questionnaire has good content validity and structural validity.

\section{Research Object}

In order to compare, this paper selects auto assembly plants as the research object, because assembly plants has the value chain, while the auto parts factory has poor profit and low employee income, so we did not choose the parts factory. This study selected four enterprises, including a private auto company in Shenzhen (started to manufacture automobile in 2003), a state-owned auto company in Zhuzhou (invested by a state-owned automobile group in Beijing, built in 2009), a 
Sino-Japanese joint venture auto company in Hubei (become a joint venture enterprise through state-owned enterprise reform in 2003) and a Sino-Japanese joint venture auto company in Guangzhou (built in 2007). To ensure the reliability of survey data, we use the method of outside factory investigation. Several graduate students waited all day outside the factory and random intercepted the workers to answer the questionnaires. The investigators explained the survey questions, and then the respondents filled in, so we got the questionnaire with almost no waste and involved as different departments as possible. In order to know the overall status of the survey enterprise, our research group also made interviews with the human resources department, trade unions and related departments and collected the enterprise culture and employee handbook. The survey was conducted from the end of June 2011 to the end of October 2011. The samples collected from the four companies are all above 80, which are 132,105, 158 and 80, and the total sample size is 475,360 of which are male, while other 115 are female, 354 of which are at the age below 31, and the other 121 are above 32 years old.

\section{RESULTS}

\section{A. Descriptive Statistics}

Table I shows the mean and correlation coefficient of main variables. It is not difficult to find that the involvement and consistency perception of organization culture is positively related with employees' job satisfaction. It can be seen that the workers' perception of involvement is far lower than the consistency perception in China auto manufacturing plants, which fits well with the actual situation. Job satisfaction is in an ordinary level, in which the income satisfaction is lowest $(M=2.13)$, followed by job prospects satisfaction $(M=2.78)$, while the working time is most satisfied $(M=3.15)$. As to the overall job satisfaction level of the four firms, the joint venture company in Hubei has lowest satisfaction $(M=2.54)$, the corporation in Shenzhen and the state-owned enterprise in Zhuzhou are fairly $(M=2.87)$, the score of the joint venture in Guangzhou is little lower $(M=2.83)$. The workers in the joint venture in Hubei are still heavily burdened, though this joint venture has went through a state-owned enterprise reform. Compared with the other three companies, the average age of employees in this enterprise is the highest, about 37 years old (other three are under 30 years old). The grassroots workers salary level is under 2000 yuan/month, which is lower than the other three enterprises.

TABLE I: DESCRIPTIVE STATISTICS

\begin{tabular}{lccccc}
\hline \multicolumn{1}{c}{ items } & $\begin{array}{c}\text { Mean } \\
\text { value }\end{array}$ & $\begin{array}{c}\text { Standard } \\
\text { deviation }\end{array}$ & 1 & 2 & 3 \\
\hline $\begin{array}{l}\text { 1 Involvement } \\
\text { perception }\end{array}$ & 2.459 & 0.555 & 1 & & \\
\hline $\begin{array}{l}\text { Consistency } \\
\text { perception }\end{array}$ & 3.012 & 0.504 & $\begin{array}{l}0.452 \\
(* *)\end{array}$ & 1 & \\
$\begin{array}{l}\text { 3 Job } \\
\text { satisfaction }\end{array}$ & 2.759 & 0.628 & $\begin{array}{l}0.469 \\
(* *)\end{array}$ & $\begin{array}{c}0.537 \\
(* *)\end{array}$ & 1 \\
\hline \hline$* * p<0.01$ & & & & &
\end{tabular}

\section{B. Tests of Hypotheses}

We define the generation as a moderate variable in this study. Because this variable is a category variable and the independent variable is a continuous one, it is lack of theoretical significance that using the interaction- moderate variable $x$ independent variable to test moderating effect Cohen, Lu Xiefeng pointed out that researchers should do group regression analysis in this case, by considering the difference of regression coefficient. If the difference is significant, the moderating effect is significant. This paper will do group regression analysis of new generation employees and traditional employees using SPSS, and then test the difference of regression coefficient using $\mathrm{R}$. The layered linear regression is shown in Table II.

TABLE II: DESCRIPTIVE STATISTICS

\begin{tabular}{|c|c|c|c|c|c|}
\hline Steps & & $\begin{array}{l}\text { New } \\
\text { generation } \\
\text { employees } \\
\text { Standardized } \\
\text { Coefficients }\end{array}$ & $\begin{array}{l}R^{2} \\
\Delta R^{2}\end{array}$ & $\begin{array}{l}\text { Traditional } \\
\text { employees } \\
\text { Standardized } \\
\text { Coefficients }\end{array}$ & $\begin{array}{l}R^{2} \\
\Delta R^{2}\end{array}$ \\
\hline \multirow{6}{*}{ Control } & Gender & -0.005 & & -0.037 & \multirow{6}{*}{$\begin{array}{l}0.262 \\
0.223\end{array}$} \\
\hline & Education & $0.141 *$ & & 0.165 & \\
\hline & Wage level & $0.206^{* *}$ & 0.096 & 0.010 & \\
\hline & $\begin{array}{l}\text { Enterprise } \\
\text { nature }\end{array}$ & $-0.192 * *$ & 0.080 & -0.147 & \\
\hline & Position & 0.009 & & 0.174 & \\
\hline & Department & 0.059 & & $-0.340 * *$ & \\
\hline Main & Involvement & $0.384 * *$ & 0.421 & $0.307 * *$ & 0.452 \\
\hline effect & Consistency & $0.346^{* *}$ & 0.408 & $0.287 * *$ & 0.412 \\
\hline
\end{tabular}

Dependent variable: job satisfaction, $* p<0.05, * * p<0.01$

The $\mathrm{p}$ value of the two models is 0.000 , in which the main effects of two independent variables are significant under the significant level of 0.01 . The standardized coefficients of two independent variables are positive, so the cultural internal integration perception both positively influence on the new generation employees' and traditional employees' job satisfaction. Hypothesis 1, 2 are verified. These two models both have strong explanation power of job satisfaction, which is $42.1 \%$ and $45.2 \%$. We also can see that the control variables such as department and position have great influence on traditional employees' job satisfaction (the explanatory is $26.2 \%$ ).

To test the influence of cultural internal integration perception both on the new generation employees' and traditional employees' job satisfaction, we conduct another layer of regression analysis on the effect of the two independent variables. After the control variables, $\Delta R^{2}$ of the new generation model is $0.225(p<0.01)$ and $\Delta R^{2}$ of the traditional model is $0.147(p<0.01)$, when the involvement perception is introduced into the models in the first step. Then $\Delta R^{2}$ of the new generation model is $0.101(p<0.01)$ and $\Delta R^{2}$ of the traditional model is $0.043(p<0.01)$, when the variables of involvement and consistency perception are introduced together into the models. It indicates that the involvement perception can explain $22.5 \%$ variation of new generation employees' job satisfaction and $22.5 \%$ variation of traditional employees', and the consistency perception can explain $10.1 \%$ variation of new generation employees' job 
satisfaction and $4.3 \%$ variation of traditional employees'. So both the involvement and the consistency perception make larger contribution to new generation employees' job satisfaction compared with traditional employees.

In order to validate hypothesis 3 and 4, the moderating effect of different generation is tested. Hypothesis $H_{01}$ : $B_{x a}-B_{c a}=0$ and $H_{02}: B_{x b}-B_{c b}=0$, in which $B x i$ is the regression coefficient of new generation group, $B c i$ is the regression coefficient of traditional group, a represents the consistency perception, $b$ represents the involvement perception. Therefore the regression equation of new generation group can be expressed as

$$
\begin{aligned}
& Y x=\beta_{01}+a B_{x a}+b B_{x b}+\xi_{x} \\
& Y c=\beta_{02}+a B_{c a}+b B_{c b}+\xi_{c}
\end{aligned}
$$

$\beta$ for constant, $\varepsilon$ for residual items. Three dumb variables are defined. 1 in dumb variables generations represents the new generation group, while 0 represents traditional group. Virtual variable generation $x$ consistency is the product of generations and the consistency perception. Virtual variable generation $x$ involvement is the product of generations and the involvement perception. The test of regression coefficients difference is done with $R$, as shown in Table III.

\begin{tabular}{|c|c|c|c|c|}
\hline $\begin{array}{l}\text { Test } \\
\text { statistic }\end{array}$ & $\begin{array}{l}\text { Estimate } \\
\text { value }\end{array}$ & $\begin{array}{l}\text { Standard } \\
\text { Deviation }\end{array}$ & $t$ & $P$ \\
\hline$\beta 02$ & 3.09484175 & $\begin{array}{l}0.001386800 \\
0\end{array}$ & $\begin{array}{l}2231.6424 \\
5\end{array}$ & $0.000000 \mathrm{e}+00$ \\
\hline$\beta 01-\beta 02$ & -0.75586549 & $\begin{array}{l}0.001788623 \\
3\end{array}$ & -422.59624 & $0.000000 \mathrm{e}+00$ \\
\hline$B c a$ & 0.30718762 & $\begin{array}{l}0.000542629 \\
3\end{array}$ & 566.10954 & $0.000000 \mathrm{e}+00$ \\
\hline$B c b$ & 0.28743547 & $\begin{array}{l}0.000635227 \\
5\end{array}$ & 452.49220 & $0.000000 \mathrm{e}+00$ \\
\hline$B x b-B c b$ & 0.07669145 & $\begin{array}{l}0.000633562 \\
8\end{array}$ & 121.04791 & $0.000000 \mathrm{e}+00$ \\
\hline$B x a-B c a$ & 0.05872590 & $\begin{array}{l}0.000730769 \\
5\end{array}$ & 80.36173 & $5.574869 \mathrm{e}-276$ \\
\hline
\end{tabular}

TABLE III: MODERATING EFFECT OF DIFFERENT GENERATION

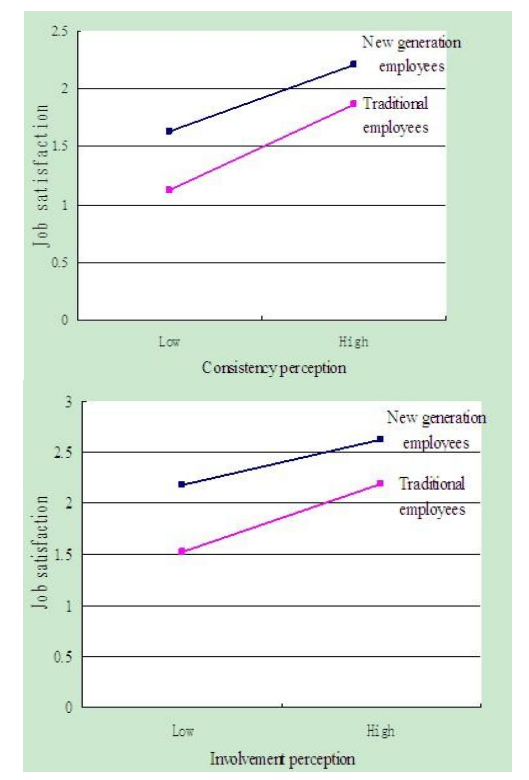

Fig. 1. Moderating effect of different generation.
It is known that the $\mathrm{p}$ value is less than 0.01 of hypothesis test $H_{01}: B_{x a}-B_{c a}=0$ and $H_{02}: B_{x \mathrm{~b}}-B_{c b}=0$, so that the null hypothesis is rejected and the difference of regression coefficients is significant. It means the generation can significantly moderate the influence of consistency and involvement perception on job satisfaction.

The regression lines of new generation employees and traditional employees which the independent variables are involvement perception and consistency perception and the dependent variable is job satisfaction are drawn, as shown in Fig. 1. With the increase of involvement perception and consistency perception, new generation employees, and traditional employees, job satisfaction is increasing, and the influence of involvement perception and consistency perception on new generation employees' job satisfaction is significantly higher than the traditional employees. So hypothesis 3,4 are verified.

\section{Conclusions And SugGestion}

\section{A. Conclusions}

Based on the theory analysis, this study describes the enterprise culture integrating internal perception and job satisfaction, analyzes their relationship, uses intergenerational differences as moderating variable, and then draws specific conclusions as follows:

- In job satisfaction indexes, employees' income satisfaction in automobile manufacturing enterprises is the lowest, and it is lower than the general level. According to the survey, the samples reflected that their wage is 1500-2500 yuan per month, which indicates that there is still a considerable distance between present wage level and their psychological expectations for physical grassroots workers.

- Involvement and consistency perception of organization culture have significant positive impact on automobile manufacturing industry employees. The result of regression analysis shows that involvement and consistency perception of organization culture explain employee job satisfaction well for the new generation of employees and traditional employees. This conclusion confirms Denison's viewpoint in China, that is, involvement and consistency perception of organization culture contribute to improve the job satisfaction. And data also shows that involvement perception puts more effect on job satisfaction than consistency perception. These provide direction for constructing enterprise internal culture in automobile manufacturing enterprises.

- The effects of the two features of organization internal integration culture on job satisfaction for new generation employees and traditional employees are different, and the effects on new generation employees are significantly higher than on traditional employees. Intergenerational differences have played a significant moderating role in the relationship between organization culture and job satisfaction. It is significant to draw the conclusion that managers should make corresponding measures on the new generation 
employees.

\section{B. Practical Implication}

Based on the research conclusion, some management practical implications are put forward.

Firstly, given the different and various requirements, companies should manage new generation employees with different methods in order to strengthen their participation motivation and the shape of grassroots team. At present, there are still many defects in the grass-roots management of auto manufacturing enterprise. For example, many of them lack staff professional career planning, employee participation in management and promotion channels; at the same time, to manage new generation employees with the traditional mode might reduce the their organizational commitment and satisfaction as a result of unable to realize their demand of self-worth, self-esteem and equality. Managers should distinguish staffs with different ages and give new generation employees reasonable guidance. It will be a good choice to keep communication smoothly on the basis of rigid principle such as working rules and regulations, to advocate public facility, to optimize the construction of grassroots quality circles and independent work team and then to improve the internal team cohesion.

Secondly, auto manufacturing enterprises should bring the grass-root labor union construction to the completion and establish a democratic communication mode with new generation employees. The grass-root labor unions are absent in the four surveyed enterprise. Although there are some feedback channels, it does not work at all. From the case of Honda strike, we can clearly learned that new generation employees have stronger rights consciousness and higher sense of participation compared with traditional employees. It reflected from the frequent strikes in car industry that strikes are workers' action to maintain their rights when their interests are violated and not be valued or solved. In response, enterprise should correctly understand the self-help activities and take some corresponding measures. All of the following will be good ideas: to improve the grass-root labor union's organizational construction, to set up two-way communication mechanism between enterprise and staff, to establish a communication mode of democracy consultation with new generation employees, then listen to their requirements and further meet their demand in participation.

\section{Limitations and Future Direction}

This study got some very important conclusions from two aspects of management theory and practice, but there are still some defects:(1) Although the sample size of every enterprise is above 80 , the more great the sample size is, the more accurate the result will be in packet analysis, so the sample size needs to be improved; (2) This study did not involve a exclusively foreign owned enterprise owing to the limited manpower and material resource. Future study needs more multiple samples; (3) Because of the limitations in sample size, the time span of sample's "generations" is large in this paper. The number of each intergenerational sample can be increased in future study. To compare each intergenerational group and get the unique characteristics, researchers should subdivide every intergenerational division and define the characteristics of new generation employees.

\section{REFERENCES}

[1] H. J. Zhu and J. P. Xu, "The study of the relationship among corporate culture, knowledge share and core capability-an empirical research based on the corporate in west-south China," Studies in Science of Science, vol. 26, pp. 820-826, August 2008

[2] D. R. Denison and A. K. Mishra, "Toward a theory of organizational culture and effectiveness," Organization Science, vol. 6, pp. 204-223, April 1995.

[3] C. F. Fey and D. R. Denison, "Organizational culture and effectiveness: Can American theory be applied in Russia," Organization Science, vol. 14, pp. 686-706, December 2003

[4] N. A. Nazir and M. A. Lone, "Validation of denison's model of organizational culture and effectiveness in the Indian context," The Journal of Business Perspective, vol. 12, pp. 49-58, December 2008.

[5] R. J. Zhang and H. Y. Li, "The study of the relationship between organization culture and firm performance," Modern Management Science, vol. 29, pp. 102-105, April 2010

[6] Y. H. Xie and B. G. He, "An eternal topic of industrial democracy and employee involvement- literature review of industrial democracy and employee involvement in China," Socialism Studies, vol. 31, pp. 86-93, July 2008.

[7] S. Q. Liu and Y. Q. Gan, "Organizational Culture and Job Satisfaction: The Moderating Effect of Personality," Journal of Peking University (natural science edition), vol. 43, pp. 251-256, April 2007.

[8] J. B. Gu and Y. Li, "Organizational culture's incentive function and its influence on employee's job satisfaction," Journal of Management, vol. 9, pp. 1274-1278, September 2009.

[9] H. C. Xu, Y. Zheng, and X. T. Huang, "Research on Chinese young people's life value," Journal of Southwest University (social sciences edition), vol. 52, pp. 35-39, October 2008.

[10] R. X. He and H. F. Xu, "The new generation of peasant workers' value change," China Youth Study, vol. 18, pp. 9-11, April 2006.

[11] X. Zhou, J. Zhang, and Z. Z. Tang, "The direct and indirect effects of the after $80 \mathrm{~s}$ generation employees' work value on the job performance," Productivity Research, vol. 25, pp. 203-204, September 2010.

[12] D. R. Denison, "Organizational culture: Can it be a key lever for driving organizational change," in The Handbook of Organizational Culture, S. Cartwright and C. Cooper, Eds. London: John Wiley \& Sons, 2000, pp. 131-142.

[13] Y. H. Xie, "A comparison analysis of China's industrial democracy and employee involvement-data from Hunan Province," Comparative Economic and Social Systems, vol. 25, pp. 129-132, February 2009.

[14] P. E. Spector, "Measurement of human service staff satisfaction: Development of the job satisfaction survey," American Journal of Community Psychology, vol. 13, pp. 639-713, April 1985.

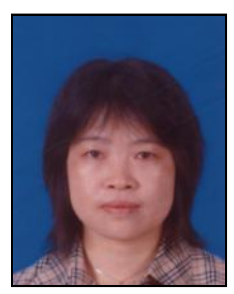

Yuhua Xie was born in Changsha, Hunan, China in 1965; She has been a professor since March 2006; graduated from Huazhong Normal University in Wuhan, Hubei Province and got a Master Degree in July 1989 and further received a Doctor's Degree of Law here in July 2004; went to Deakin University in Australia twice as a visiting scholar during July 2006 to July 2007, January to June in 2009. The research major is labor relations, HRM. She is a professor of Management School, Hunan University, China. She has published more than 80 papers and finished ten books with her fellow teams. For example,(1)Baogang. He and Yuhua Xie, "Wal-mart's Trade Union in China" Economic and Industrial Democracy,vol.33, pp. 421-440, July 2011 (2) Yuhua Xie, Ying Zhu, Malcolm Warner, "Exploring the Reality of Educated Middle Managers' Capability and Involvement in Human Resource Management in China" The International Journal of Human Resource Management, forthcoming. Her current and previous research interests are mainly on labor relations, HRM, employee participation, CSR, corporation culture, etc. Prof. Xie is the director of the Research Center of Corporation Society Responsibility and Labor Relations in Hunan University. 


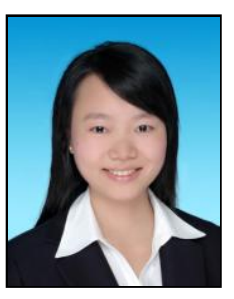

Jia Chen was born in Quzhou, Zhejiang, China in 1988; graduated from Management School of Hunan University and got a Master Degree by research of Management in February 2013. The research interest is labor relations and HRM, corporation culture. She works in Quzhou Branch of China Mobile in Quzhou, Zhangjiang now. She has published 2 articles: (1) Yuhua. Xie, Jia. Chen, Peipei Chen, and Qiaoling Xiao, "An Empirical Analysis of Industrial Collective Bargaining Outcomes in China: An Example from the Wuhan Restaurant and Catering Industry", Comparative Economic and Social Systems, vol.28, pp. 55-67, September 2012.(2)Yuhua Xie, Mei. Zhang and Jia. Chen, "On the Functions and Influencing Factors of Collective Consultation: Documentary Comparison and Lessons", Journal of China Institute of Industrial Relations, vol. 26, pp. 27-31, September 2012.

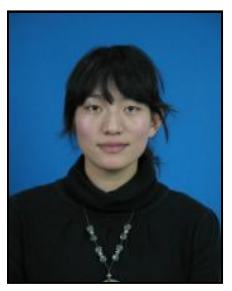

PeipeiChen was born in Changsha, Hunan, China in 1988; graduated from Business Administration and Tourism Management School of Yunnan University, Kunming, Yunnan and now in the second year for master degree in Management School of Hunan University. The research interest is labor relations, HRM. She is a postgraduate in Changsha, Hunan. She has published 1 article as a third writer: Yuhua. Xie, Jia. Chen, Peipei Chen, and Qiaoling Xiao, "An Empirical Analysis of Industrial Collective Bargaining Outcomes in China: An Example from the Wuhan Restaurant and Catering Industry", Comparative Economic and Social Systems, vol.28, pp. 55-67, September 2012. Her current and previous research interests are mainly on labor relations, HRM, employee participation, etc. 